DOI 10.37882/2223-2982.2020.10-2.01

\title{
ФОРМИРОВАНИЕ ПРОФЕССИОНАЛЬНОЙ КОМПЕТЕНТНОСТИ СТУДЕНТОВ ПЕДАГОГИЧЕСКОГО ВУЗА В ОБЛАСТИ НАУЧНО- ИССЛЕДОВАТЕЛЬСКОЙ ДЕЯТЕЛЬНОСТИ'
}

\section{FORMATION OF PROFESSIONAL COMPETENCE OF STUDENTS \\ OF A PEDAGOGICAL UNIVERSITY IN THE FIELD OF SCIENTIFIC RESEARCH ACTIVITY}

\section{Abramova}

Summary: This article is devoted to the study of the problem of the formation of professional competence of students of a pedagogical university in the field of research activities. The paper presents the experience of solving this problem on the example of the student scientific association «Modern problems of the study, training and education of children with disabilities».

Keywords: higher education, competence, research activities.

\author{
Абрамова Инна Викторовна \\ К.п.н., доцент, Мордовский государственный \\ педагогический университет имени М.Е. Евсевьева \\ (2. Саранск) \\ iva-76@yandex.ru
}

Аннотация: Настоящая статья посвящена исследованию проблемы формирования профессиональной компетентности студентов педагогического вуза в области научно-исследовательской деятельности. В работе представлен опыт решения данной проблемы на примере деятельности научного студенческого объединения «Современные проблемы изучения, обучения и воспитания детей с ограниченными возможностями здоровья».

Ключевые слова: высшее образование, компетентность, научно-исследовательская деятельность.
$\Pi$ роблема профессиональной компетентности студентов педагогического вуза в области научноисследовательской деятельности и эффективной организации научной работы студентов является актуальной и требует целенаправленной и систематической работы по ее решению. Поэтому исследование, направленное на разработку научно-методического сопровождения процесса ее формирования, значимо и необходимо.

В настоящее время происходит становление системы психолого-педагогического сопровождения процесса образовательной интеграции детей с ограниченными возможностями здоровья. Перед педагогами все чаще встают вопросы, связанные с определением теоретикометодологических основ проектирования новых технологий процесса сопровождения, выбора из них таких, которые способны обеспечить коррекционно-развивающее воздействие на детей с различными отклонениями в развитии, необходимое для их успешной образовательной и социальной интеграции, встраивания новых технологий психолого-педагогического сопровождения в учебно-воспитательный процесс с использованием современной образовательной организации. На эти вопросы в определенной степени призваны ответить научно-исследовательские работы студентов. Организация научно-исследовательской работы студентов в рамках решения актуальных задач образования и сопровождения лиц с ограниченными возможностями здоровья позволяет не только формировать способность и готовность к постановке научной проблемы, определения методологического аппарата исследования, проектированию этапов исследования, интерпретации его результатов, но и вырабатывать навыки профессиональной деятельности в рамках осваиваемой основной образовательной программы. Прежде всего, это владение профессиональными знаниями о категориях детей с ограниченными возможностями здоровья и нормативно-правовых основах предоставления им образовательных услуг, готовность осуществлять психологопедагогическое и медико-социальное сопровождение детей дошкольного и младшего школьного возраста с 
ограниченными возможностями здоровья, а также взаимодействие с родителями детей с ограниченными возможностями здоровья и педагогами в процессе такого сопровождения, способность проектировать индивидуальные образовательные маршруты и индивидуальные коррекционно-развивающие программы, осуществлять мониторинг коррекционно-образовательного процесса. Тем самым, повышается качество профессиональной подготовки студентов. Результаты научного поиска студентов, выполненные с учетом новейших исследований и разработок в области специальной педагогики и практико-ориентированные, также могут оказать помощь педагогам-практикам в решении проблем обучения и воспитания детей с ограниченными возможностями здоровья.

В исследованиях отечественных методологов Е.В. Бережновой, В.И. Загвязинского, В.В. Краевского в качестве основных компонентов исследовательской деятельности будущего педагога обозначены понимание направленности поисковой деятельности как творческой, продуктивной, предусматривающей не только привлечение уже известной информации, но и поиск оригинальных и эффективных решений; общенаучная и профессионально-предметная эрудированность; общекультурный кругозор, личностный творческий потенциал, готовность к нестандартным подходам и решениям, сформированность волевых и морально-психологических качеств: честности, настойчивости, увлеченности, критичности; знание методологии педагогического исследования [3; 4].

Для формирования обозначенных компонентов необходимо создание определенных условий и соответствующей образовательной среды в вузе. Отдельные аспекты формирования информационной составляющей исследовательской деятельности, возможности организации исследовательской деятельности в условиях сетевого взаимодействия представлены в работах наши коллег С.В. Архиповой, Н.В. Рябовой $[2 ; 6 ; 7]$.

Традиционной формой формирования профессиональной компетентности студентов педагогического вуза в области научно-исследовательской деятельности во многих вузах является работа в научно-проблемных и исследовательских группах, при этом организационно-содержательные аспекты такой работы очень разнообразны. Представим опыт работы студенческой научно-исследовательской группы «Современные проблемы изучения, обучения и воспитания детей с ограниченными возможностями здоровья», созданной и функционирующей на факультете психологии и дефектологии Мордовского государственного педагогического университета имени М.Е. Евсевьева.

Цель деятельности данного студенческого научно- исследовательского объединения: формирование и совершенствование профессионально-педагогических компетенций студентов в области научно-исследовательской деятельности по проблемам изучения, обучения и воспитания детей с ограниченными возможностями здоровья.

Научно-исследовательская группа «Современные проблемы изучения, обучения и воспитания детей с ограниченными возможностями здоровья» осуществляет свою деятельность с 2013-2014 учебного года (6 лет). Создание данной группы обусловлено процессами модернизации российского образования и, как следствие, необходимостью совершенствования процессов изучения, обучения и воспитания детей с ограниченными возможностями здоровья разного возраста. Основной контингент группы составляют студенты факультета психологии и дефектологии направлений подготовки бакалавров по Психолого-педагогическому образованию и Специальному (дефектологическому) образованию, прежде всего 3-4 курсов, которые выполняют курсовые и выпускные квалификационные работы под руководством научных руководителей группы, а также 1-2 курсов, которые проявили активность и интерес к научно-исследовательской деятельности в рамках ежегодных мероприятий, организуемых кафедрой (студенческое научное мероприятие «Рекламная акция - «Мы и есть наука»», Неделя науки для студентов факультета психологии и дефектологии). Наиболее активную часть научного студенческого объединения составляют магистранты указанных направлений подготовки, которые умело сочетают собственную научно-исследовательскую деятельность и накопленный практический опыт в рамках профессиональной деятельности. При этом сохраняется преемственность в научном руководстве данными магистрантами еще на этапе их бакалаврской подготовки, на основе общности их научных интересов и научных руководителей. Такой подход к организации научно-исследовательской деятельности позволяет добиваться достаточно высоких результатов.

Основными формами работы со студентами в рамках деятельности научного студенческого объединения являются активизация участия студентов в международных и всероссийских конкурсах, проектах, олимпиадах, подготовка и публикация студентами самостоятельно или совместно с преподавателями монографий, научных статей в рецензируемых журналах из перечня ВАК, привлечение студентов к оформлению заявок и выполнении научно-исследовательских грантов, к проведению научно-практических мероприятий на базе вуза.

В качестве основной формы и технологии взаимодействия участников данного студенческого научного объединения являются научные консультации, дискуссии, совместные проекты и публикации. Одним из эффектив- 
ных форм является проведение студенческого научного мероприятия «Рекламная акция - «Мы и есть наука»». Цели данной акции: привлечение студентов 1-2 курсов к научно-исследовательской работе; презентация основных направлений научно-исследовательской деятельности со студентами, осуществляемой преподавателями факультета психологии и дефектологии; знакомство студентов с деятельностью научно-исследовательских лабораторий, научно-практических центров, студенческих научных объединений, организованных на факультете психологии и дефектологии; выявление знаний студентов об основах научной организации труда и научно-исследовательской деятельности. Акция проходит в три этапа. На первом этапе осуществляется презентация основных направлений научно-исследовательской работы со студентами: деятельность в составе научно-исследовательской лаборатории «Интегрированное обучение детей в современной системе образования», научнопрактического центра «Ресурсный центр интегрированного образования»; выполнение фундаментальных и прикладных исследований (магистерские, кандидатские и докторские диссертации); реализация в Центре продленного дня индивидуальных программ коррекционноразвивающего обучения с детьми; включение студентов в работу студенческих научных объединений, и включения в деятельность творческих коллективов, осуществляющих работу по грантам разного уровня. На втором этапе проводится анкетирование студентов 1-2 курса; основная тема анкеты «Нужна ли наука современному студенту?». На третьем этапе проводится тестирование студентов 1-2 курса «Основы научно-исследовательской работы» $[1 ; 5]$.

Необходимо отметить, что данное мероприятие проводят студенты старших курсов, по результатам акции расширяется состав студенческих научных объединений за счет привлечения в них студентов 1-2 курса.

Сотрудничество данного научного объединения с другими вузами, научными и образовательными организациями, общественными и профессиональными объединениями по направлениям исследований обеспечивается посредством организации сотрудничества со студентами и преподавателями ведущих педагогических вузов Российской Федерации, в частности, Нижегородским государственным педагогическим университетом имени Козьмы Минина (г. Нижний Новгород), Московским педагогическим государственным университетом, Московским городским педагогическим университетом (г. Москва), Ульяновским государственным педагогическим университетом им. И.Н. Ульянова (г. Ульяновск). Прежде всего, сотрудничество осуществляется в рамках организации и проведения ежегодной Всероссийской заочной студенческой научно-практической конференции «Коррекционно-развивающая среда как средство социализации лиц с отклонениями в развитии». Кон- ференция проводится с целью обобщения и актуализации современных достижений в области специального и инклюзивного образования, обсуждения процессов модернизации российской системы образования, расширения возможностей обмена научным опытом молодых исследователей, развития диалога и укрепления научных связей студентов ведущих вузов России. Студенты из указанных вузов готовят публикации, участвуют в обсуждении проблем образования лиц с ограниченными возможностями здоровья.

Активное сотрудничество студентов данного студенческого научного объединения осуществляется с педагогическими коллективами образовательных организаций г. о. Саранск и Республики Мордовия. В первую очередь с такими организациями, как ГБОУ РМ «Саранская общеобразовательная школа для детей с ограниченными возможностями здоровья» и МДОУ «Детский сад № 91 компенсирующего вида» г. о. Саранск. Данные организации являются экспериментальными площадками, где студенты изучают опыт практической деятельности и выполняют собственные экспериментальные исследования по проблемам изучения, обучения и воспитания детей с ограниченными возможностями здоровья, по заказу данных организаций выполняются выпускные квалификационные работы.

Экспериментальные исследования, которые выполняют студенты данного объединения в рамках подготовки выпускных квалификационных работ, выполнения научно-исследовательских работ в рамках сетевых грантов и других проектов, всегда имеют практико-ориентированную составляющую, представленную в формате практических рекомендаций по совершенствованию коррекционно-образовательного процесса в образовательных организациях. Это могут быть программы индивидуального сопровождения ребенка с ограниченными возможностями здоровья, программы внеурочной деятельности, формы работы с родителями детей с проблемами в развитии, комплекс педагогических условий по реализации инклюзивной практики и др., апробированные в конкретной образовательной организации и внедренные в ее учебно-воспитательный процесс. Как правило, результаты таких исследований и разработок публикуются и представляются широкому кругу заинтересованных субъектов образования лиц с ограниченными возможностям здоровья, что позволяет переносить положительный опыт внедрения результатов научных исследований и разработок в образовательную практику других организаций других регионов.

Несомненно, студенческая научно-исследовательская работа, прежде всего, включена в учебный процесс и дополняет его, поэтому большинство исследований выполняется в соответствии с учебными планами и программами и предусматривает выполнение заданий 
исследовательского характера на занятиях и в ходе практики, курсовых проектов (работ) и выпускных квалификационных работ. Такая организация позволяет сформировать у студента готовность к самообразованию, поиску нестандартных вариантов решения учебно-профессиональных задач, применения в конкретной практической ситуации навыков научной организации труда. Но, также научно-исследовательская деятельность студентов может быть организована в форме работы в научно-исследовательских лабораториях, научно-проблемных и исследовательских группах под руководством конкретного научного руководителя, и в данном случае ключевую роль играет выраженная мотивация студента к научной деятельности, что создает условия не только для профессионального становления, но и личностного развития студента, расширения кругозора, эрудиции, развития нестандартного мышления, способности оперативно решать поставленные перед ними задачи, настойчивости, целеустремленности, совершенствования информационно-коммуникационной компетентности, коммуникативной культуры, расширения межличностных контактов. Данные надпрофессиональные навыки проявляются в процессе участия в конкурсах научно-исследовательских работ, научных проектов, публикациях и т. д.

В рамках реализации стратегических документов социально-экономического развития РФ исследования, проводимые студентами научного студенческого объединения, направлены на решение важных задач по созданию специальных образовательных условий для обучающихся с особыми образовательными потребностями, по совершенствованию профессиональной подготовки практических работников образования, по внедрению инновационных технологий в практику обучения и воспитания детей с ограниченными возможностями здоровья. Готовность к научно-исследовательской деятельности и способность творчески подходить к проектированию коррекционно-развивающей среды как средства социализации лиц с отклонения в развитии студенты данной группы продемонстрировали в рамках участия в таких значимых мероприятиях, как Всерос- сийская профессиональная олимпиада студентов «Я профессионал» и Всероссийский конкурс молодежных авторских проектов и проектов в сфере образования, направленных на социально-экономическое развитие российских территорий «Моя страна - моя Россия». Опыт участия в таких мероприятиях позволяет студентам совершенствовать навыки научно-исследовательской деятельности и презентации ее результатов.

В качестве перспектив дальнейшей работы студенческого научного объединения можно выделить два вектора:

1. общие подходы к организации научно-исследовательской деятельности студентов: совершенствование научно-исследовательской работы студентов в целях реализации приоритетных направлений развития научно-исследовательской и инновационной деятельности вуза; освоение студентами технологии самостоятельного научного поиска, решения учебно-профессиональных задач; формирование способности работать в научных коллективах; взаимообмен опытом организации и проведения научной работы среди студентов;

2. конкретные задачи организации научно-исследовательской деятельности студентов в предстоящем учебном году: включить студентов группы в заявки на выполнение научно-исследовательских работ в рамках грантов международных и всероссийских научных фондов; организовать участие студентов в конкурсных мероприятиях всероссийского и международного уровня; публиковать результаты студенческих исследований в сборниках материалов всероссийских и международных научно-практических конференций, в научных журналах, в журналах из перечня ВАК; организация и проведение международных и всероссийских конкурсов студенческих научных проектов на базе кафедры специальной педагогики и медицинских основ дефектологии и факультета психологии и дефектологии.

\section{ЛИТЕРАТУРА}

1. Абрамова, И.В. Значение научно-исследовательской деятельности студентов для формирования профессиональной компетентности/ И.В. Абрамова // Гуманитарные науки и образование. - 2013. - № 2(13). - С. 49-53.

2. Архипова, С.В. Информационная компетентность педагога-дефектолога / С.В. Архипова, А.С. Чаприна // Гуманитарные науки и образование. - 2019. Том 10. - № 2. - C. 7-14.

3. Бережнова, Е.В. Основы учебно-исследовательской деятельности студентов: Учебник для студентов средних учебных заведений/ Е.В. Бережнова, В.В. Краевский. - М. : Издательский центр «Академия», 2008. - 128 с.

4. Загвязинский, В.И. Исследовательская деятельность педагога / В. И. Загвязинский. - М.: Академия, 2006. - 176 с.

5. Лаврентьева М.А., Гришина О.С. Подготовка супервизора дефектологической практики на базе НПЦ «Ресурсный центр интегрированного образования» // Современные наукоемкие технологии. - 2017. - № 1. - C. 114-119. -URL: http://www.top-technologies.ru/ru/article/view?id=36566 (дата 06 ращения: 


\subsubsection{0).}

6. Рябова, Н.В. Подготовка педагогов для инклюзивного образования / Н.В. Рябова, О. И. Карпунина // Высшее образование в России. - 2016. - № 10 (205). - С. 119-124.

7. Рябова, Н.В. Сетевое взаимодействие образовательных организаций как необходимое условие подготовки педагогических кадров/ Н. В. Рябова // Гуманитарные науки и образование. - 2015. - № 3(23). - С.107-112.

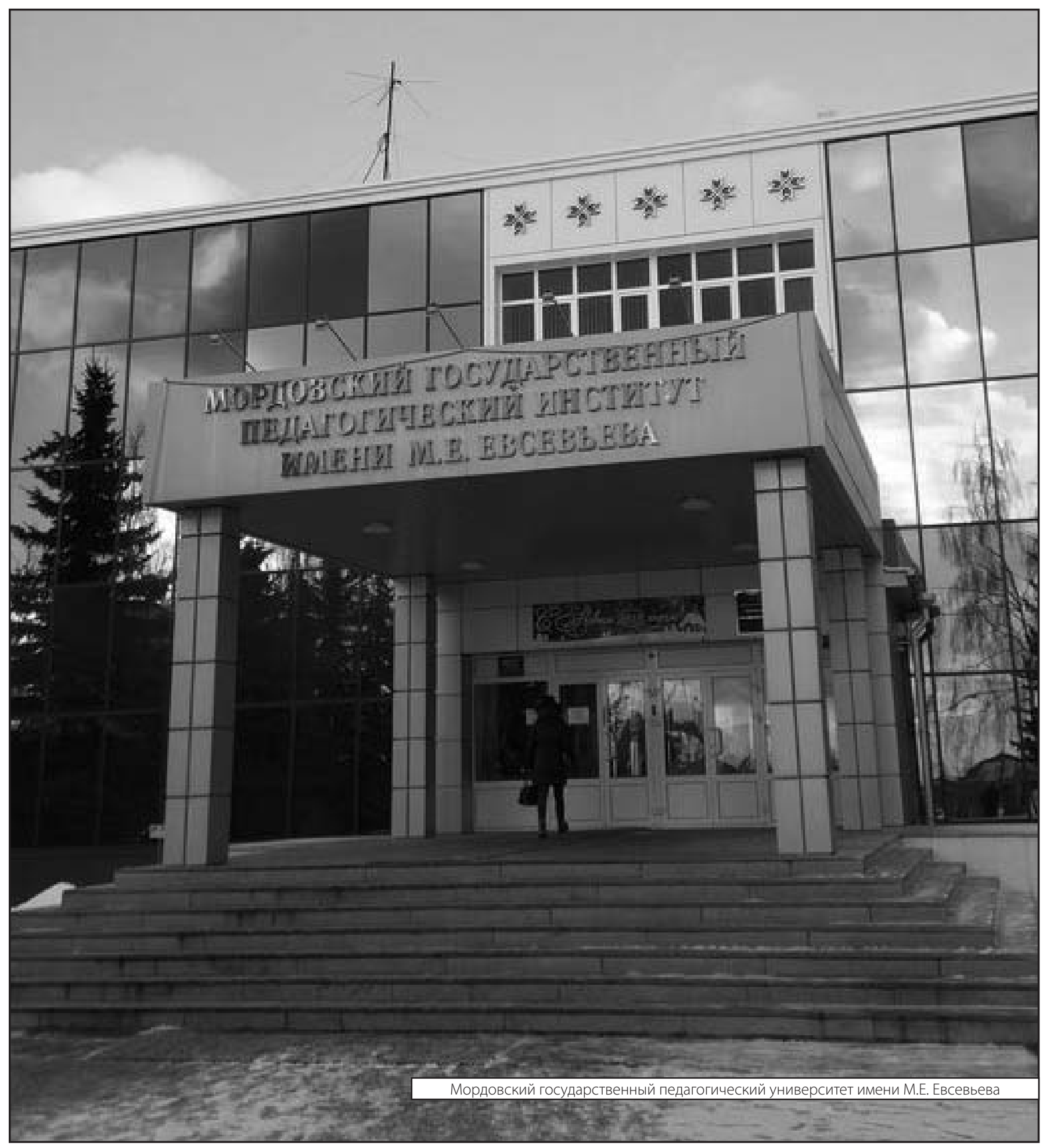

